\title{
Effect of an Exercise Program That Includes Deadlifts on Low Back Pain
}

\author{
Samuel C. Fischer, Darren Q. Calley, and John H. Hollman
}

\begin{abstract}
Clinical Scenario: Low back pain is a common condition for the general population with $29 \%$ of adults having low back pain within the last 3 months. A deadlift is described as a free weight exercise in which a barbell is lifted from the floor in a continuous motion by extending the knees and hips. For those without low back pain, the deadlift was found to have the highest muscle activation of paraspinal musculature compared with other exercises. There are a limited number of studies that investigate the usefulness of incorporating deadlifts as part of a rehabilitation program for low back pain. Clinical Question: For those who live with low back pain, is an exercise routine that includes a deadlift a viable treatment option to improve pain and/or function? Summary of Key Findings: The literature search yielded 3 total studies meeting the inclusion and exclusion criteria: 1 randomized control trial, 1 secondary analysis of a randomized control trial, and 1 cohort study. Exercise programs that include deadlifts can yield improvements in both pain and function for those living with low back pain but were not found to be more beneficial than low load motor control exercises. Those with lower pain levels and higher baseline lumbar extension strength may be most appropriate to participate in an exercise program that includes deadlifts. Further research is needed to compare exercise programs that include deadlifts to other interventions for those living with low back pain. Clinical Bottom Line: There is minimal evidence that exercise programs that included deadlifts are a clinically effective option for the treatment of low back pain for both pain scores and functional outcome measures. Strength of Recommendation: Level B evidence exists that exercise programs that include deadlifts are a clinically effective option for the treatment of low back pain for both pain scores and functional outcome measures.
\end{abstract}

Keywords: deadlift, low back pain, rehabilitation

\section{Clinical Scenario}

Low back pain (LBP) is a common condition for the general population with $29 \%$ of adults having LBP within the last 3 months. ${ }^{1}$ A deadlift is described as a free weight exercise in which a barbell is lifted from the floor in a continuous motion by extending the knees and hips. ${ }^{2}$ For those without LBP, the deadlift was found to have the highest muscle activation of paraspinal musculature compared with other exercises, ${ }^{3}$ which may be relevant for those with LBP, who demonstrate increased slumped posture with sitting and decreased lumbar multifidus activation. ${ }^{4}$ There are limited studies that investigate the usefulness of incorporating deadlifts as part of a rehabilitation program for mechanical low back pain (MLBP).

\section{Focused Clinical Question}

For those who live with MLBP, is an exercise program that includes deadlifts a viable treatment option to improve pain and/ or function?

\section{Summary of Search Strategy, "Best Evidence" Appraised, and Key Findings}

- The literature search yielded 3 total studies meeting the inclusion and exclusion criteria: 1 randomized control trial

The authors are with the Mayo Clinic Physical Therapy Orthopaedic Residency, Mayo Clinic School of Health Sciences, Mayo Clinic College of Medicine and Sciences, Mayo Clinic, Rochester, MN, USA. Fischer (sfischer@ activeptandsports. com) is corresponding author.
(RCT), 1 secondary analysis of a randomized control trial, and 1 cohort study.

- Exercise programs that include deadlifts can yield improvements in both pain and function for those living with LBP but were not found to be more beneficial than low load motor control exercise.

- People living with LBP that have lower reported pain levels and higher baseline lumbar extension strength may be most appropriate to participate in an exercise program that includes deadlifts.

- Further research is needed to compare exercise programs that include deadlifts to other interventions for those living with LBP.

\section{Clinical Bottom Line}

There is level B evidence that exercise programs that included deadlifts are a clinically effective option for the treatment of MLBP for both pain scores and functional outcome measures.

\section{Strength of Recommendation}

Level B evidence exists that exercise programs that include deadlifts are a clinically effective option for treatment of MLBP for both pain scores and functional outcome measures. (Levels of evidence determined based upon the Oxford Centre for Evidence-Based Medicine, 2011.) A level B evidence grade is defined as "consistent level 2 or 3 studies or extrapolations from level 1 studies." 


\section{Search Strategy}

\section{PICO Framework}

- Patient group: MLBP

- Intervention: exercise program that included deadlifts

- Comparison: none

- Outcome: pain and/or functional outcome measures

\section{Sources of Evidence Searched}

- PubMed

- Google Scholar

- PEDro

- Cochrane Library

- Additional resources obtained via review of reference lists

\section{Inclusion and Exclusion Criteria}

\section{Inclusion}

- Subjects diagnosed with MLBP

- Use of a deadlift variation included in an exercise program

- Use of a pain scale or functional outcome measure

- Symptom duration of 3 months

- English language

- RCT, cohort designs

\section{Exclusion}

- No deadlift related treatment options

- No diagnosis of LBP or non-MLBP

- No pain scale and/or functional outcome measure

- Symptoms less than 3 months

- Case study, case control, expert opinion, or case series designs

- Non-English studies

\section{Search Results}

A total of 3 relevant studies were identified based on the previously mentioned search strategies ${ }^{2,6,7}$ and are listed in Table 1 (based on the Oxford Centre for Evidence-Based Medicine 2011 Levels of Evidence).

\section{Best Evidence}

The 3 stated studies were identified based on inclusion and exclusion criteria and selected for inclusion in this CAT (Table 2). Selected studies were chosen because they included subjects with MLBP, used exercise programs that included deadlift, used a pain scale or functional outcome measure, had symptoms of at least 3 months, and were written in the English language.

\section{Implications for Practice, Education, or Research}

The purpose of this CAT was to assess if exercise programs that include deadlifts can be a viable option to improve pain and
Table 1 Summary of Study Designs

\begin{tabular}{|c|c|c|}
\hline $\begin{array}{l}\text { Level of } \\
\text { evidence }\end{array}$ & Study design & Study \\
\hline 2 & Randomized control trial & Aasa et $\mathrm{al}^{6}$ \\
\hline 2 & $\begin{array}{l}\text { Secondary analysis of randomized } \\
\text { control trial }\end{array}$ & $\begin{array}{l}\text { Berglund } \\
\text { et } \mathrm{al}^{2}\end{array}$ \\
\hline 3 & Cohort & Welch et $\mathrm{al}^{7}$ \\
\hline
\end{tabular}

function in those living with MLBP. Overall, the studies included in this CAT provided minimal evidence that exercise programs that include deadlifts can be beneficial for both pain and function for those living with MLBP.

Aasa et $\mathrm{al}^{6}$ demonstrated that a high load lifting (HLL) exercise routine that consisted of progressive deadlifting and low load motor (LLM) control exercises both resulted in significant improvements in pain intensity, strength, and endurance. The groups were similar for all baseline characteristics except for the Patient Specific Functional Score (PSFS), which was significantly lower in the LLM (3.8 [1.4] and 4.8 [1.4], respectively). Participants in the LLM group (unadjusted mean score $=8.0$ ) showed a significantly greater improvement in the PSFS (unadjusted mean score $=7.3$ ) compared with participants in the HLL group at a 12-month follow-up $(P<.001)$. There was no difference between groups in pain intensity at a 12-month follow-up $(P=.505)$. Overall, after 12 months, about $65 \%$ experienced a meaningful improvement in perceived pain intensity (minimal important change of $30 \%$ or greater).

Berglund et $\mathrm{al}^{2}$ was a secondary analysis of data from the Aasa et $\mathrm{al}^{6}$ study to investigate what characteristics of patients with MLBP in the HLL group predicted to benefit from a progressive deadlift routine. Activity scores based on PSFS increased from 4.8 (1.3) to 6.8 (2.2). Disability scores based on the Roland-Morris Disability Questionnaire decreased from 7.1 (4.1) to 3.8 (3.9). Pain intensity based on the visual analog scale decreased from 42.6 (23.5) to 22.2 (21.1). Results of this analysis showed that with high disability and pain intensity scores and low performance of the Biering-Sorensen test, participants were less likely to benefit from deadlift training. The Biering-Sorensen test for hip and back extension muscle endurance and strength was the best predictor for success (greater than $60 \mathrm{~s}$ ). Low initial pain intensity (less than $60 \mathrm{~mm}$ on a visual analog scale) was the second-best predictor for success with a progressive deadlift routine.

Welch et $\mathrm{al}^{7}$ found that a free weight resistance training routine that included deadlifts was effective to improve pain, disability, and quality of life scores in a group with chronic MLBP. Pain, measured by the visual analog scale, improved from 4.5 (2.2) at baseline to $1.3(1.4)$ at 16 weeks. Disability, measured by the Oswestry Disability Index, improved from 22.9 (1.2) at baseline to 5.4 (5.7) at 16 weeks. Quality of life scores, measured by EuroQOL-5d V.2, improved from $0.7(0.2)$ at baseline to $0.9(0.1)$ at 16 weeks. In addition, lumbar paraspinal muscle fat infiltration at the L3/L4 and L4/L5 levels was significantly reduced $(P<.05)$ following the interventions at 16 weeks. However, there was not a control group for comparison within this cohort study, so comparisons to other control or intervention groups cannot be drawn.

The previously mentioned studies included some limitations. Aasa et $\mathrm{al}^{6}$ had a highly homogeneous participant group, so generalizability to other populations is difficult. All participants were labeled as having nociceptive LBP, but the reliability for identifying mechanistic pain groups was not investigated. Finally, 
Table 2 Characteristics of Included Studies

\begin{tabular}{|c|c|c|c|}
\hline Characteristic & Aasa et al $^{6}$ & Berglund et $\mathrm{al}^{2}$ & Welch et al $^{7}$ \\
\hline Study design & RCT & Secondary analysis of RCT & Cohort \\
\hline $\begin{array}{l}\text { Number of } \\
\text { participants }\end{array}$ & 70 & 35 & 30 \\
\hline $\begin{array}{l}\text { Group } \\
\text { descriptions }\end{array}$ & $\begin{array}{l}\text { LLM control exercises and HLL exercise } \\
\text { routine }\end{array}$ & HLL $^{6}$ & No comparison group \\
\hline Age range & LLM: 42 (11) y and HLL: 42 (10) y & $42(10) \mathrm{y}$ & females: 40 (12) y and males are $40(10)$ y \\
\hline Gender & $\begin{array}{l}\text { LLM: } 19 \text { females and } 16 \text { males } \\
\text { HLL: } 20 \text { females and } 15 \text { males }\end{array}$ & 20 females and 15 males & 11 females and 19 males \\
\hline Interventions & $\begin{array}{l}12 \text { treatment sessions over } 8 \mathrm{wk} \text {. All } \\
\text { participants were also educated on pain } \\
\text { mechanisms. LLM was encouraged to } \\
\text { complete } 10 \text { repetitions } 2-3 \times / \mathrm{d} \text {. HLL } \\
\text { included progressive deadlift routine with } \\
\text { a physical therapist selected initial weight } \\
\text { that was completed } 12 \text { sessions over } 8 \mathrm{wk} \text {. }\end{array}$ & $\begin{array}{l}12 \text { treatment sessions over } 8 \text { wk which } \\
\text { included education on pain mechanisms } \\
\text { and HLL with progressive deadlift } \\
\text { routine. }^{6}\end{array}$ & $\begin{array}{l}16 \mathrm{wk} \text {, progressive, free weight-based } \\
\text { resistance training program that includes } \\
\text { deadlift. }\end{array}$ \\
\hline $\begin{array}{l}\text { Outcome } \\
\text { measures }\end{array}$ & $\begin{array}{l}\text { Primary outcome measures were PSFS } \\
\text { and average pain intensity over the last } 7 \mathrm{~d} \\
\text { using the visual analog scale. }\end{array}$ & $\begin{array}{l}\text { Outcome measures included PSFS, } \\
\text { Roland-Morris Disability Questionnaire, } \\
\text { and pain visual analog scale. Predictive } \\
\text { variables also included pain-related fear } \\
\text { of movement, } 3 \text { tests of trunk muscle } \\
\text { endurance, and a movement control test. }\end{array}$ & $\begin{array}{l}\text { Outcome measures included visual ana- } \\
\text { log pain scale, Oswestry Disability Index, } \\
\text { Euro-Qol V2 quality of life measure, } \\
\text { biomechanical analysis of bodyweight } \\
\text { squat movements, maximum strength, } \\
\text { lumbar endurance, and lumbar paraspinal } \\
\text { fat infiltration. }\end{array}$ \\
\hline Main findings & $\begin{array}{l}\text { Both interventions had significant } \\
\text { improvement in pain intensity but there } \\
\text { were no significant between group dif- } \\
\text { ferences }(P=.505) \text {. LLM (3.8-8.0) had a } \\
\text { significant improvement in PSFS com- } \\
\text { pared with HLL }(4.8-7.3) \text {. }\end{array}$ & $\begin{array}{l}\text { Participants with less disability, less pain } \\
\text { intensity, and higher performance on the } \\
\text { Biering-Sorensen test at baseline benefit } \\
\text { from deadlift training. The Biering-Sor- } \\
\text { ensen test was the best predictor of } \\
\text { success. }\end{array}$ & $\begin{array}{l}\text { Pain ( } 72 \% \text { improvement), disability ( } 76 \% \\
\text { improvement), and quality of life }(27 \% \\
\text { improvement) significantly improved } \\
\text { along with reduction in fat infiltration and } \\
18 \% \text { increase in lumbar endurance. }\end{array}$ \\
\hline Level of evidence & 2 & 2 & 3 \\
\hline $\begin{array}{l}\text { Validity score } \\
\text { (PEDro) }\end{array}$ & $7 / 10$ & $7 / 10$ & Not applicable \\
\hline Conclusion & $\begin{array}{l}\text { LLM may be superior with PSFS out- } \\
\text { comes compared with HLL, but both } \\
\text { groups can significantly improve pain } \\
\text { intensity scores. }\end{array}$ & $\begin{array}{l}\text { Professionals who use deadlift for indi- } \\
\text { viduals with mechanical low back pain } \\
\text { should test for sufficient back extensor } \\
\text { strength and low pain intensity levels at } \\
\text { baseline. }\end{array}$ & $\begin{array}{l}\text { A free weight-based resistance training } \\
\text { program that included deadlifts can be } \\
\text { utilized to improve pain, disability, and } \\
\text { quality of life in people living with low } \\
\text { back pain. }\end{array}$ \\
\hline
\end{tabular}

Abbreviations: HLL, high load lifting; LLM, low load motor; PSFS, Patient-Specific Functional Scale; RCT, randomized control trial.

there was no placebo control group, so the observed effects could be from chance as well. The Berglund et $\mathrm{al}^{2}$ study was a secondary analysis of the same population from Aasa et $a{ }^{6},{ }^{6}$ which is not preferred to generate predictive models. The authors wrote that the stated prediction was made to guide future prospective studies. Finally, the Welch et $\mathrm{al}^{7}$ study was a cohort design, so there was no comparison group to compare findings in a similar timeframe. This decreases the generalizability and significance of the findings.

This CAT also had limitations within its analysis. There is only one RCT to the writer's (SCF) literature review that met inclusion and exclusion criteria for this CAT. The other 2 trials were a secondary analysis of the RCT and a cohort trial without a comparison group. Further research, specifically more RCTs, is needed to generalize conclusions with higher clinical relevance and stronger significance. Future research should prioritize both shortand long-term results of an exercise routine that prioritize progressive deadlifting for participants with a variety of forms of LBP compared with control groups. Also, future research should consider specific loading principles with deadlifts and confirmation of responders to a deadlift routine.
The purpose of this CAT was to assess if exercise programs that include deadlifts can be a viable option to improve pain and function in those living with MLBP. Based on the included studies, there is minimal evidence that exercise programs that included deadlifts can improve pain and function with those with MLBP. Patients with higher baseline lumbar and hip extension strength and endurance with lower baseline levels of pain had a higher likelihood of benefiting from deadlift training for treatment of LBP. ${ }^{2}$ Benefits from exercise programs that include deadlift for treatment of LBP can be seen as early as 8 to 16 weeks. ${ }^{6,7}$ Programs that include deadlifts have not been studied extensively within different subgroups of LBP. More research, specifically RCT, is required to make clinically significant conclusions about prioritizing deadlifting routines for the treatment of MLBP along with other types of LBP.

\section{Acknowledgments}

This work was completed as part of the Mayo Clinic Physical Therapy Orthopaedic Residency. The authors have no conflict of interest to disclose. 


\section{References}

1. Centers for Disease Control and Prevention. 2014 . Severe headache or migraine, low back pain, and neck pain among adults aged 18 and over, by selected characteristics: United States, selected years 19972013. https://www.cdc.gov/nchs/data/hus/2014/046.pdf. Accessed April 1, 2020.

2. Berglund L, Aasa B, Hellqvist J, et al. Which patients with low back pain benefit from deadlift training? J Strength Cond Res. 2015; 29(7):1803-1811. PubMed ID: 25559899 doi:10.1519/JSC.00000 00000000837

3. Colado JC, Pablos C, Chulvi-Medrano I, et al. The progression of paraspinal muscle recruitment intensity in localized and global strength training exercises is not based on instability alone. Arch Phys Med Rehabil. 2011;92(11):1875-1883. PubMed ID: 22032222 doi:10.1016/j.apmr.2011.05.015

4. Gordon R, Bloxham S. A systematic review of the effects of exercise and physical activity on non-specific chronic low back pain.
Healthcare. 2016;4(2):22. PubMed ID: 27417610 doi:10.3390/ healthcare 4020022

5. Centre for Evidence-Based Medicine. Oxford Centre for Evidencebased Medicine-Levels of Evidence (March 2009). February 19, 2016. https://www.cebm.net/2009/06/oxford-centre-evidence-basedmedicine-levels-evidence-march-2009/. Accessed May 5, 2020.

6. Aasa B, Berglund L, Michaelson P, et al. Individualized low-load motor control exercises and education versus a high-load lifting exercise and education to improve activity, pain intensity, and physical performance in patient with low back pain: a randomized control trial. J Orthop Sports Phys Ther. 2015;45(2):77-85. PubMed ID: 25641309 doi:10.2519/jospt.2015.5021

7. Welch N, Moran K, Antony J, et al. The effects of a free-weight-based resistance training intervention on pain, squat biomechanics and MRI-defined lumbar fat infiltration and functional cross-sectional area in those with chronic low back. BMJ Open Sport Exerc Med. 2015;1(1):e000050. PubMed ID: 27900136 doi:10.1136/bmjsem2015-000050 